\title{
Asuhan Keperawatan Pada Perempuan Dewasa Dengan Diagnosa Gastritis
}

\author{
Mona Ariestia \\ Akper Kesdam 1/BB Padang Indonesia \\ Email : monaariestia03@gmail.com
}

\begin{abstract}
Abstrak
Gastritis merupakan peradangan pada mukosa lambung yang ditandai dengan tidak nyaman pada perut bagian atas, rasa mual, muntah, nafsu makan menurun, atauu sakit kepala. Gastritis merupakan salah satu jenis kasus yang umunya diderita oleh kalangan remaja, disebabkan oleh berbagai faktor diantaranya pola makan atau gaya hidup dan perilaku untuk mencegah terjadinya gastritis. Bahaya penyakit gastritis jika dibiarkan terus menerus akan merusak fungsi lambung dan dapat meningkatkan resiko untuk terkena kanker lambung hingga menyebabkan kematian. Dari dinas kesehatan kota padang pada tahun 2015 penyakit gastritis berada pada urutan ke-2 setelah penyakit rematik yaitu 13.453 jiwa. Di RS.TK III Dr. Reksodiwiryo padang kejadian gastritis tahun 2015 tercatat sekitar 98 orang dan terjadi peningkatan pada tahun 2016 menjadi 181 orang. Tujuan penelitian ini untuk mengetahui bagaimana penerapan asuhan keperawatan pada pasien gastritis. Desain penelitian yang digunakan adalah studi kasus dan jenis penelitian deskriptif. Hasil penelitian didapatkan pada Ny. S mengeluh sakit perut, nyeri pada ulu hati, mual dan pusing. Menurut teori, diagnosa keperawatan yang mungkin muncul sebanyak empat diagnosa. Pada kasus ditemukan tiga diagnosa. Rencan keperawatan sesuai NIC, sedangkan evaluasi keperawatan sesuai dengan NOC dimana satu diagnosa yang belum teratasi seperti nyeri dan dua diagnosa yang teratasi sebagian yaitu pemenuhan nutrisi klien dan gangguan tidur. Saran untuk rumah sakit agar dapat melakukan pembinaan lebih lanjut terhadap pelaksanaan yang belum teratasi nyeri pada pasien gastritis.
\end{abstract}

Kata Kunci : Asuhan Keperawatan, Perempuan dewasa, diagnosa keperawatan, Gastritis

\begin{abstract}
Gastritis is an inflammation of the gastric mucosa that is uncomfortable in the upper stomach, nausea, vomiting, decreased appetite, or headaches. Gastritis is one type of case commonly suffered by adolescents, which is caused by various factors including diet or lifestyle and behavior to prevent gastritis. The danger of gastritis if allowed to continue will damage stomach function and can increase the risk of developing gastric cancer and causing death. From the Padang city health office in 2015, gastritis was in the 2nd place after rheumatic disease, namely 13,453 people. At RS.TK III Dr. Reksodiwiryo padang, the incidence of gastritis in 2015 was recorded at around 98 people and an increase in 2016 to 181 people. The purpose of this study was to determine how the application of nursing care to gastritis patients. The research design used is a case study and descriptive research type. The results of the study were found at $N y$. S complaints of stomach pain, heartburn, nausea and dizziness. According to the theory, there are as many as four possible nursing diagnoses. In this case three diagnoses were found. The nursing plan was in accordance with the NIC, while the nursing evaluation was in accordance with the NOC where one unresolved diagnosis such as pain and two partially resolved diagnoses were the client's nutritional fulfillment and sleep disorders. Suggestions for the hospital to be able to provide further guidance on the implementation of which pain has not been resolved in gastritis patients.
\end{abstract}

Keywords: Nursing Care, Adult Women, Nursing Diagnosis, Gastritis 


\section{PENDAHULUAN}

Gastritis adalah suatu kondisi di mana lapisan kulit dalam lambung meradang atau membengkak.Gastritis atau juga sering disebut sebagai radang lambung, dapat muncul secara mendadak atau berlangsung dalam waktu yang lama.Orang awam sering menyebut gastritis adalah Maag,padahal gastritis pada dasarnya berbeda dari Maag.

Gastritis adalah peradangan mukosa lambung yang bersifat akut, kronik,dan local. Penyakit ini disebabkan oleh makanan, obat-obatan, zatkimia, stres, dan bakteri .

Penyakit gastritis yang dikenal dengan gangguan saluran pencernaan bagian atas ini banyak dikeluhkan masyarakat dikarenakan mengacu pada peradangan lambung. Gastritis terdiri dari dua tipe yaitu gastritis akut dan gastritis kronis. Faktor penyebab gastritis akut dan kronis adalah pola makan yang tidak teratur, konsumsi obat penghilang nyeri jangka panjang, konsumsi alkohol, merokok, stres fisik, stres psikologis dan infeksi bakteri.

Kondisi ini tidak berbahaya dan dapat disembuhkan dengan pengobatan tertentu. Namun, dalam beberapa kasus, penyakit gastritis adalahh kondisi yang dapat menjadi risiko kanker Lambung

Penyakit gastritis ini tersebar di seluruh dunia dan bahkan diperkirakan diderita lebih dari 1,7 milyar orang. Menurut World Health Organization (WHO) angka kejadian gastritis di dunia diantaranya inggris $22 \%$, cina $31 \%$, jepang $14,5 \%$, kanada $35 \%$, dan prancis $29,5 \%$. Di dunia insiden gastritis sekitar 1,8-2,1 juta dari jumlah penduduk setiap tahun. Insiden terjadinya gastritis di Asia Tenggara sekitar 583,635 dari jumlah penduduk setiap tahunnya.

Dalam penelitian yang dilakukan oleh Purba (2017) mengatakan bahwa salah satu masalah kesehatan yang sering terjadi dimasyarakat adalah penyakit saluran cerna seperti gastritis. Penyakit ini bila tidak segera diatasi dengan cara yang tepat maka dapat menimbulkan komplikasi hingga resiko perdarahan selain itu juga dapat menimbulkan tukak lambung, kanker lambung sehingga dapat menyebabkan kematian

Dikuatkan oleh penelitian sebelumnya, Ningsih (2018) menghasilkan penelitian bahwa gastritis merupakan suatu peradangan local atau menyebar pada mukosa lambung yang berkembang bila mekanisme protektif mukosa dipenuhi dengan bakteri atau bahan iritan,gastritis disebut radang lambung dapat menyerang setiap orang dengan segala usia.

Didukung oleh penelitian sebelumnya, Putriana (2019) menghasilkan penelitian bahwa Gastritis biasanya dikenal dengan maag yang merupakan suatu peradangan pada mukosa lambung yang disebabkan oleh faktor iritasi. Gastritis merupakan gangguan yang paling sering ditemui di klinik karena diagnosisnya hanya berdasarkan gejala klinis. Penyakit ini sering dijumpai timbul secara mendadak biasanya ditandai dengan rasa mual dan muntah nyeri epigastrium dan nafsu makan menurun. 
Faktor yang akan terjadi Jika penderita gastritis tidak segera diatasi akan merasakan nyeri diulu hati yang hebat, namun hanya bersifat sementara, jika terjadi peradangan kronis pada penderita Gastritis dapat menyebabkan perubahan struktur.

Lapisan lambung dan beresiko berkembang menjadi kanker. Maka Peran perawat sebagai care provider yaitu sebagai pemberi asuhan keperawatan yang sangat dibutuhkan bagi penderita Gastritis dalam merawat penyakitnya. Seperti upaya kuratif yang dapat dilakukan perawat yaitu memberikan asuhan keperawatan dengan dengan merencanakan intervensi dan mengaplikasikan intervensi tersebut sesuai dengan permasalahan yang dikeluhkan oleh klien.

Adapun rencana keperawatan yang akan peneliti lakukan untuk menangani masalah yaitu meliputi pengkajian yang berfokus pada tanda dan gejala atau keluhan klien seperti nyeri pada epigastrium, mual dan muntah, perdarahan terselubung maupun nyata. Kemudian perawat merencanakan intervensi keperawatan yang dapat dilakukan yaitu lakukan pengkajian nyeri secara komprehensif, observasi reaksi nonverbal dari ketidaknyamanan, gunakan teknik komunikasi terapeutik untuk mengetahui pengalaman nyeri. Perawat memiliki peran dalam pemberian asuhan keperawatan pada klien Gastritis secara optimal, propesional dan komprehensif, sedangkan pada aspek rehabilitative perawat berperan dalam memulihkan kondisi klien dan menganjurkan pada keluarga untuk control kerumah sakit serta memberikan pendidikan kesehatan seperti teratur dalam minum obat, kurangi mengkonsumsi makanan yang dapat menyembabkan penyakit kambuh, seperti makanan pedas, asam jika nyeri dirasakan lakukan teknik relaksasi napas dalam.

Berdasarkan Latar Belakang Diatas, didapatkan bahwa kasus gastritis termasuk kasus yang berbahaya dan mengancam nyawa. Maka peneliti tertarik untuk meneliti Dengan Judul "Asuhan Keperawatan wanita dewasa dengan diagnosa Gastritis berkaitan dengan nyeri akut".

\section{METODE}

Penelitian ini adalah penelitian kualitatif, sampel didalam penelitian diambil hanya satu orang yang akan dilakukan pengkajian terkait Gastritis.

\section{HASIL PENGKAJIAN}

\section{a) Identitas Klien}

\section{Tabel 4.1}

\section{Pengkajian Identitas Klien}

\begin{tabular}{|c|c|}
\hline Identitas Klien & Klien \\
\hline Nama & Nn.S \\
\hline Umur & $21 \mathrm{Th}$ \\
\hline Jenis Kelamin & Perempuan \\
\hline Pendidikan & SMA \\
\hline Agama & Islam \\
\hline Suku bangsa & Minang, Indonesia \\
\hline Alamat & $\begin{array}{l}\text { Jalan kampung jua nomor } \\
44\end{array}$ \\
\hline $\begin{array}{l}\text { Status } \\
\text { perkawinan }\end{array}$ & Belum Menikah \\
\hline Cara masuk & Melalui IGD \\
\hline Yang mengirim & Orang tua \\
\hline Alasan masuk & $\begin{array}{l}\text { Nn } \mathrm{S} \text { mengatakan nyeri } \\
\text { pada ulu hati, nafsu makan } \\
\text { menurum, dan setiap kali } \\
\text { makan merasakan mual, } \\
\text { sering bersendawa }\end{array}$ \\
\hline Diagnose medik & Gastritis \\
\hline Keluarga terdekat & Orạng Tụa \\
\hline
\end{tabular}

\section{B. Riwayat Kesehatan}

Tabel 4.2

Riwayat Kesehatan 


\begin{tabular}{|c|c|}
\hline $\begin{array}{c}\text { Riwayat } \\
\text { Kesehatan }\end{array}$ & Klien \\
\hline $\begin{array}{l}\text { Keluhan } \\
\text { Utama }\end{array}$ & $\begin{array}{l}\text { Penderita mengeluh selama } \\
2 \text { hari ini nafsu makannya } \\
\text { menurun,jika penderita telat } \\
\text { makan perut nya terasa sakit } \\
\text { dibagian epigastrium. }\end{array}$ \\
\hline $\begin{array}{l}\text { Riwayat } \\
\text { Kesehatan } \\
\text { Sekarang }\end{array}$ & $\begin{array}{l}\text { Penderita mengatakan } \\
\text { Badan terasa lemas. Dan } \\
\text { penderita juga merasakan } \\
\text { nyeri dibagian ulu hati Saat } \\
\text { dilakukan pemeriksaan fisik } \\
\text { didaapatkan hasil :TD:120/70 } \\
\text { mmhg Nadi: } 80 \mathrm{x} / \mathrm{i}, \mathrm{RR} \\
20 \mathrm{x} / \mathrm{i} \text {, Suhu: } 37 \mathrm{x} / \mathrm{i}\end{array}$ \\
\hline $\begin{array}{l}\text { Riwayat } \\
\text { Kesehatan } \\
\text { Dahulu }\end{array}$ & $\begin{array}{lr}\text { Pada riwayat } & \text { kesehatan } \\
\text { dahulu } & \text { penderita } \\
\text { mengatakan } & \text { permah } \\
\text { mengalami } & \text { penyakit } \\
\text { Gastritis } \pm 2 \text { tahun tahun } \\
\text { yang lalu }\end{array}$ \\
\hline $\begin{array}{l}\text { Riwayat } \\
\text { Keluarga }\end{array}$ & $\begin{array}{l}\text { penderita mengatakan tidak } \\
\text { ada anggota keluarganya } \\
\text { yang mengalami penyakit } \\
\text { keturunan dan penyakit } \\
\text { yang menular. }\end{array}$ \\
\hline
\end{tabular}

Pemeriksaan Fisik

Keadaan umum :Composmentis Cooperatif,

Tanda-tanda vital

Tekanan Darah : 120/70 mmhg

Suhu $\quad: 37^{\circ} \mathrm{C}$

Nadi $\quad: 80 \mathrm{x} / \mathrm{menit}$

Pernapasan : $20 \mathrm{x} /$ menit

\section{Pada hasil pemeriksaan Abdomen}

\begin{tabular}{|l|l|}
\hline Abdomen & \multicolumn{1}{|c|}{ Klien } \\
\hline Inspeksi & $\begin{array}{l}\text { Tidak ada pembesaran pada } \\
\text { abdomen klien, dan tidak } \\
\text { adanya benjolan dan } \\
\text { jaringan parut }\end{array}$ \\
\hline Palpasi & Terdapat nyeri tekan \\
\hline Perkusi & Adanya timpani \\
\hline Auskultasi & $\begin{array}{l}\text { Suara Bising usus klien } \\
<30 x / i \text { terdengar normal }\end{array}$ \\
\hline
\end{tabular}

\section{Tabel}

\section{Analisa Data}

p-ISSN :2657-2435

\begin{tabular}{|c|c|c|}
\hline DATA FOKUS & ETIOLOGI & MK \\
\hline DS: & Obat obatan & Nyeri akut \\
\hline Nn.S mengatakan & & \\
\hline badannya terasa & Menggangu & \\
\hline lemas danmual & pembentukan & \\
\hline dannmuntah setiap & sawat mukosa & \\
\hline kali makan & lambung & \\
\hline P: Nyer & & \\
\hline dirasakan ketika & Mermunukan & \\
\hline telat makan dan & bamer & \\
\hline stress meningkat & lambung & \\
\hline Q: Nyer & terhadap asam & \\
\hline dirasakan seperti & dan pepsin & \\
\hline tertusuk tusuk & & \\
\hline $\begin{array}{l}\text { R: Nyen } \\
\text { dirasakan di }\end{array}$ & inflamasi & \\
\hline $\begin{array}{l}\text { dirasakan di } \\
\text { abdomen kinin }\end{array}$ & Nyeri akut & \\
\hline bagian atas & & \\
\hline S: Skala Nyeri 5 & & \\
\hline T: Nyen dirasakan & & \\
\hline hilang timbul & & \\
\hline $\begin{array}{l}\text { kadang menetap } \\
\text { DO: }\end{array}$ & & \\
\hline$\checkmark \mathrm{Nn}$ S tampak & & \\
\hline lemah & & \\
\hline Nn.S tampak & & \\
\hline meringis & & \\
\hline Nn.S tampak & & \\
\hline gelisah & & \\
\hline Tanda Tanda Vital & & \\
\hline TD: $120 / 70 \mathrm{mmhg}$ & & \\
\hline Nadi: $80 \mathrm{x} / \mathrm{i}$ & & \\
\hline $\mathrm{RR}-20 \mathrm{x} / \mathrm{i}$ & & \\
\hline Suhrer $37^{\circ} \mathrm{C}$ & & \\
\hline
\end{tabular}

\section{PEMBAHASAN}

Berdasarkan hasil pengkajian yang dilakukan tentang keperawatan pada wanita dewasa dengan diagnosa Gastritis berkaitan dengan gangguan rasa nyaman nyeri pada bulan Juli, peneliti mengambil kesimpulan sebagai berikut :

\section{A. Pengkajian}

Berdasarkan hasil pengkajian didapatkan Nn.K mengalami Gatritis dengan keluhan nyeri pada ulu hati, mual dan muntah klien menderita Gastritis sejak 2 tahun yang lalu akan tetapi manifestasi klinis yang khas pada klien dengan Gastritis tidak ditemukan pada Nn.S. 
Pada pengkajian hidung klien tidak ditemukan pernapasan cuping hidung pada pemeriksaan mulut dan tenggorokan pada Nn.S tidak ada peradangan tonsil, pada pemeriksaan leher tidak terdapat pembesaran vena jugularis dan tidak ada peradangan pada kelenjer getah bening. Pada pemeriksaan dada/thorax pada Nn.S tidak ada edema paru, pleura dan juga batuk produktif pada paru-paru saat diauskultasi didapatkan vesikuler (+), ictus cordis terlihat di ICS VII linea aksilaris anterior sinistra, dan di ICS VII linea aksilaris anterior sinistra, batas kanan linea parasternalis dekstra, suara jantung terdengar lup dup, pada pemeriksaan abdomen Nn.S tidak ditemukan adanya acites dan edema, dan saat dipalpasi terdapat nyeri tekan pada epigastrium. Pada pemeriksaan ektremitas Nn.S tidak terdapat edema perifer.

\section{B. Diagnosa yang muncul}

Nyeri akut berhubungan dengan iritasi mukosa lambung

C. Intervensi

Intervensi keperawatan yang direncanakan dalam teori hanya beberapa yang diintervensikan tergantung pada masalah keperawatan yang ditemukan dan kondisi itu sendiri.

D. Implementasi

Implementasi keperawatan disesuaikan dengan rencana tindakan yang telah peneliti susun. Semua perencanaan diimplementasikan oleh peneliti.

\section{E. Evaluasi}

Hasil evaluasi dilakukan pada bulan juli dalam bentuk SOAP implementasi yang dilakukan masalah teratasi.

\section{SARAN}

Penelitian ini hanya meneliti satu variabel saja dan dengan responden yang relatif sedikit, sehingga hanya menggambarkan hasil penelitian yang sederhana, untuk itu, agar penelitian lanjutan menggunakan jumlah responden yang lebih besar dan dengan cakupan wilayah kerja yang lebih luas.

\section{DAFTAR PUSTAKA}

Dinarti. 2009. Dokumentasi Keperawatan. Jakarta: CV. Trans Info Media.

Diyono. 2013. Keperawatan Medikal Bedah Sistem Pencernaan. Jakarta: Kencana

DKK. 2015. Penyakit terbanyak di kota padang. Padang.

Hidayat, A. Alimul. 2014. Metode Penelitian dan Teknik Analisis Data. Jakarta: Salemba Medika

Maqassary. 2015. Penyakit terbanyak dari WHO. inggris

Nanda. 2015. Diagnosa Keperawatan. Jakarta: EGC.

Nian. 2015. Asuhan Keperawatan Pada Gangguan Sistem Gastrointestinal. Jakarta Timur: CV. Trans Info Media. 
Nursalam. 2009. Metodologi Penelitian Ilmu

Keperawatan: Pendekatan Praktis.

Jakarta: Salemba Medika.

Notoadmojo. 2012. Metodologi Penelitian

Kesehatan. Jakarta: Rineka Cipta.

Ode, La S. 2012. Asuhan Keperawatan

Gerontik. Yogyakarta: Nuha Medikal.

Ratu, Adrian R. 2013. Penyakit Hati, Lambung, Usus, dan Ambeien. Yogyakarta: Nuha Medika.

Suratun. 2010. Asuhan Keperawatan Klien Gangguan Sistem Gastrointestinal. Jakarta: CV. Trans Info Media.

Syaifuddin. 2014. Anatomi dan Fisiologi Tubuh Manusia. Jakarta: EGC.

Utomo Prayogo. 2009. Apresiasi Penyakit Pengobatan Secara Tradisional dan Moderen. Jakarta: Rineka Cipta. 
Jurnal Ilmiah Cerebral Medika, Vol.1.No 1

Vol.1.No 1 ( 2019)

p-ISSN :2657-2435 